\title{
Correction to: Evidence for Dialects in Three Captive Populations of Common Marmosets (Callithrix jacchus)
}

\author{
Yvonne Zürcher $^{1}$ (D) Judith M. Burkart ${ }^{1}$
}

Published online: 24 February 2021

(C) Springer Science+Business Media, LLC, part of Springer Nature 2021

\section{Correction to: Int J Primatol (2017) 38:780-793 https://doi.org/10.1007/s10764-017-9979-4}

The original article unfortunately contained mistakes. The changes and corrections are shown below:

\section{Methods}

- As variation in the amplitude could be mainly influenced by body posture and head tilt, we have now excluded the parameter "shimmer" from the analysis.

- We have corrected some irregularities in the data set.

We therefore provide here the results with the corrected data and without shimmer. Although the numbers in some results change, the main conclusion of the original paper remains the same.

The online version of the original article can be found at https://doi.org/10.1007/s10764-017-9979-4

\section{Yvonne Zürcher}

yvonne.zuercher@uzh.ch

1 Department of Anthropology, University of Zurich, 8057 Zürich, Switzerland 


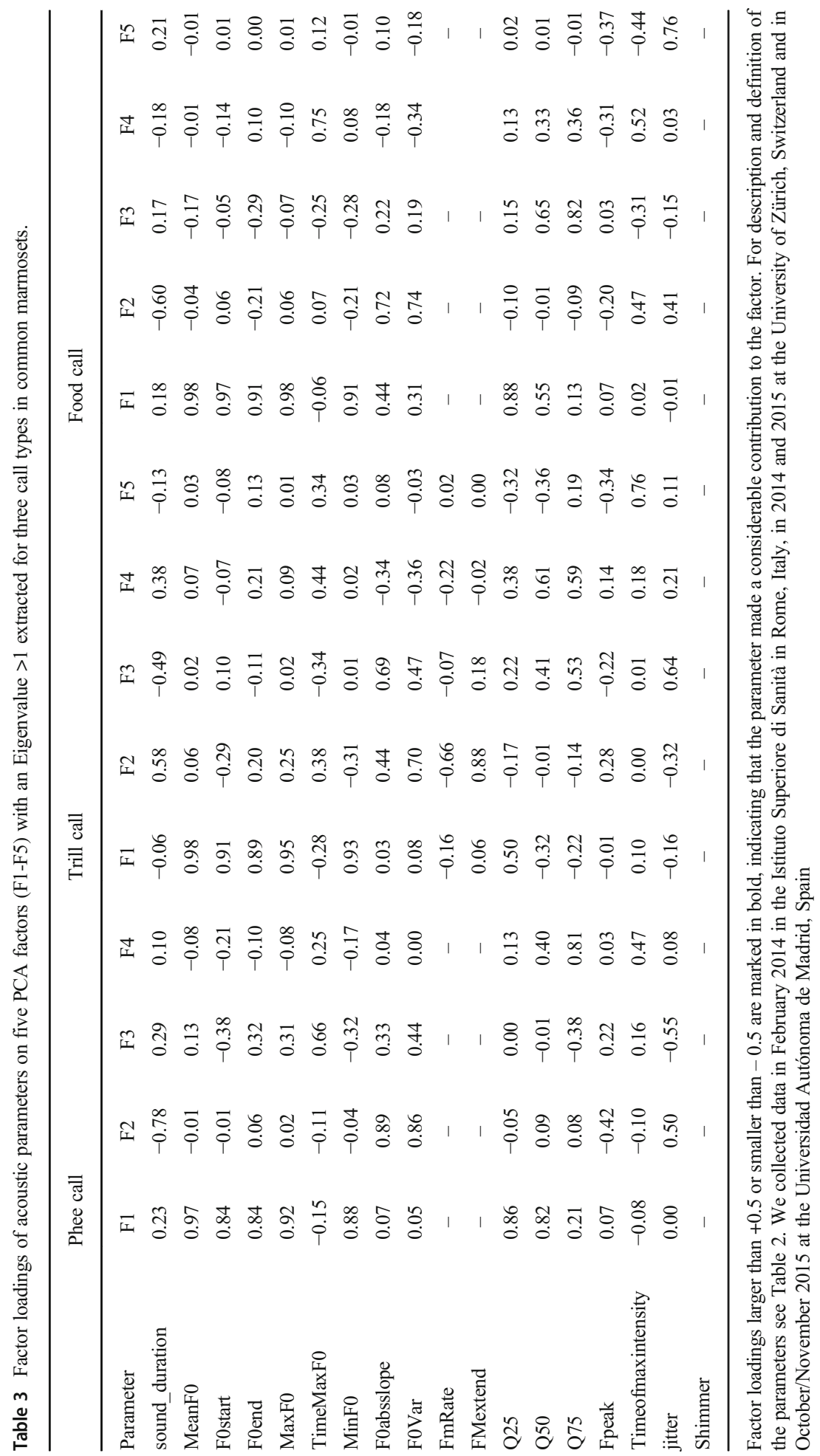




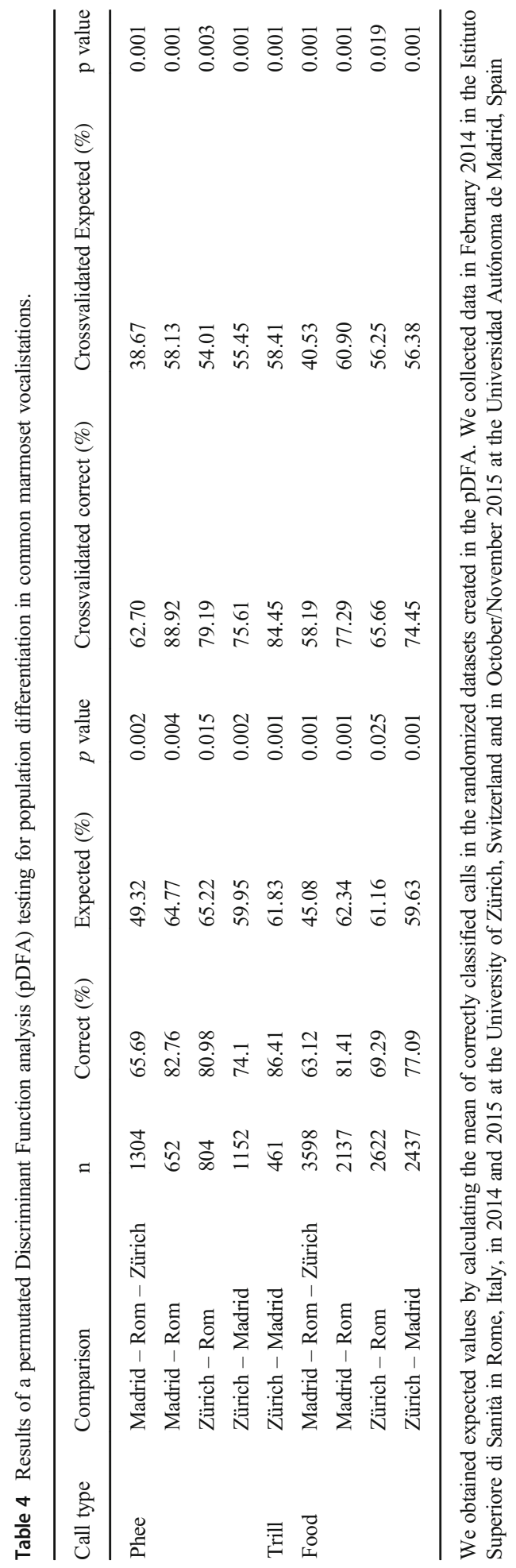




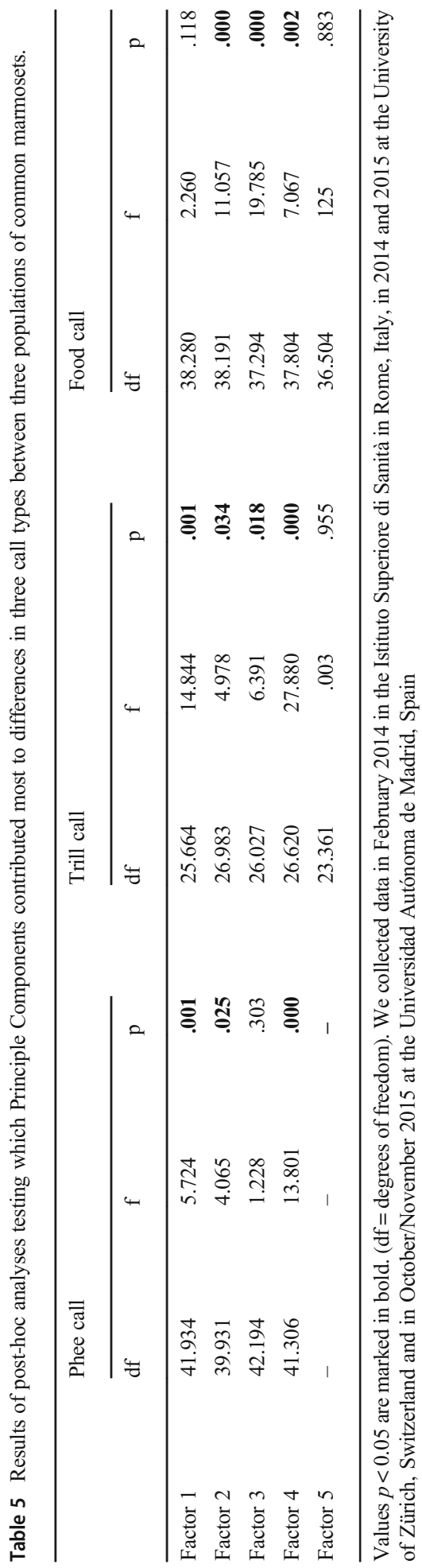




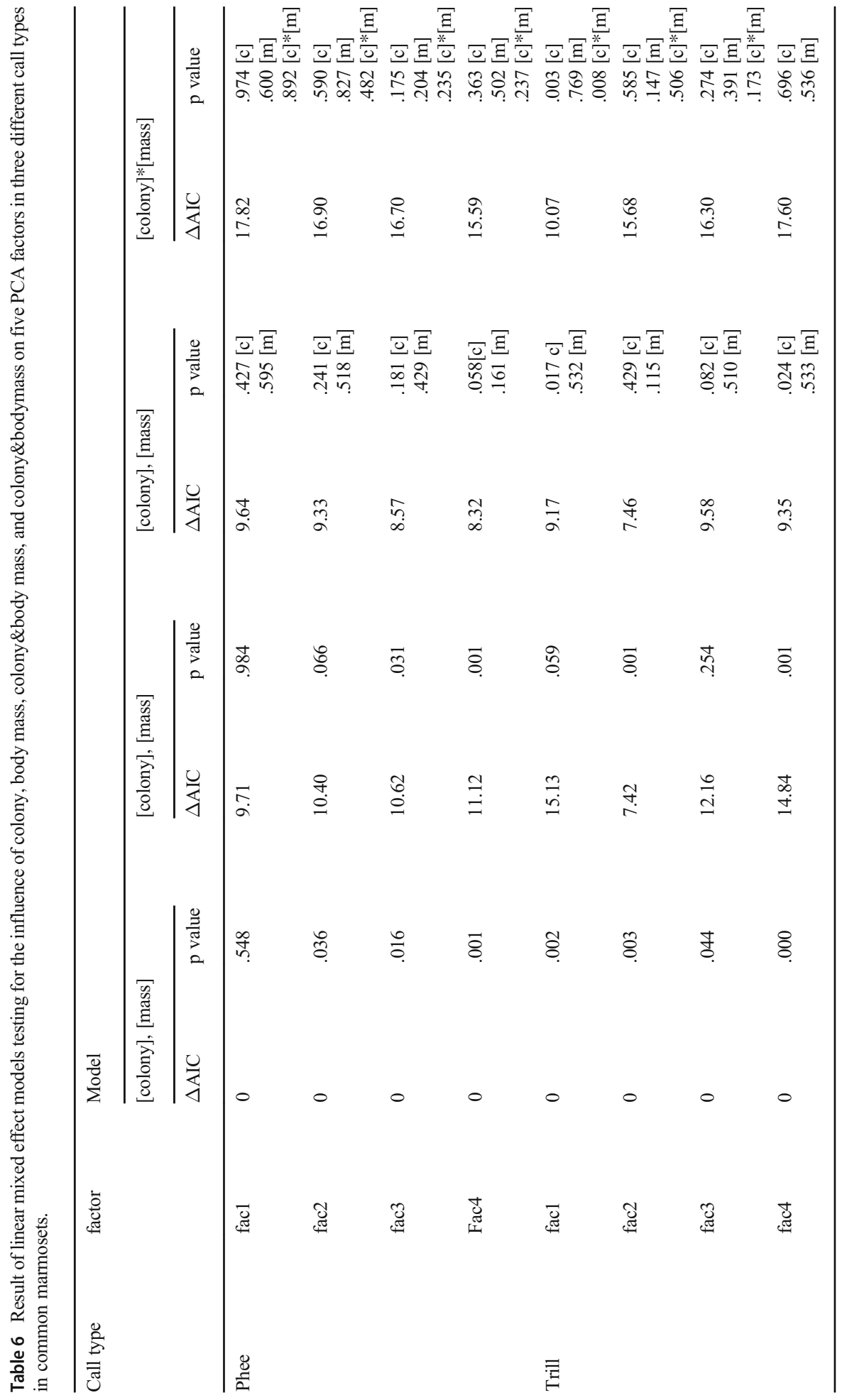




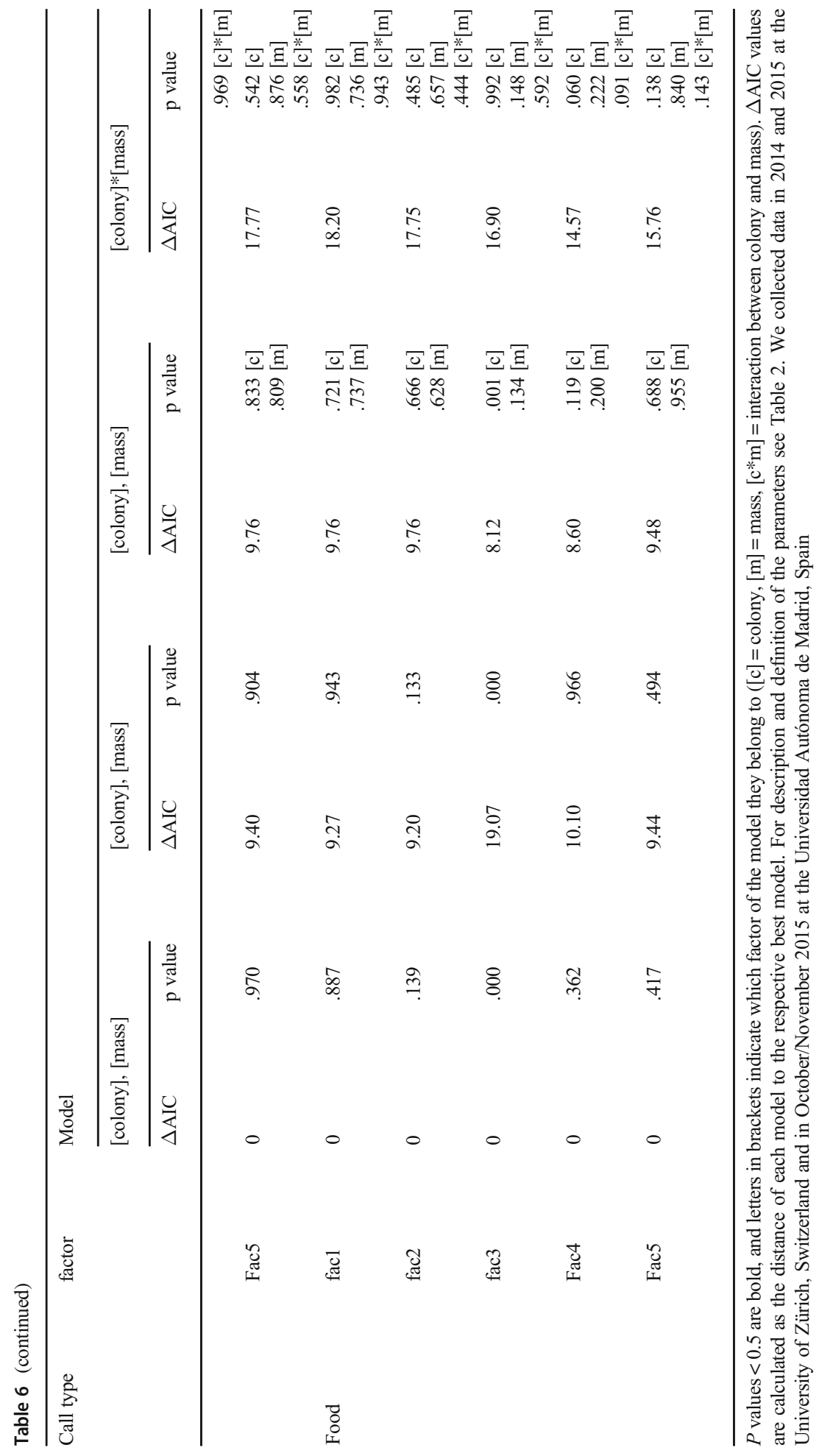

